\title{
A clinical study of alopecia areata and it's dermatoscopic correlation in a tertiary care hospital
}

\author{
K Sumohita ${ }^{1^{*}}$, M Madhavi Latha $^{2}$, T Praveena $^{3}$ \\ ${ }^{1}$ Post graduate, ${ }^{2}$ Professor, ${ }^{3}$ Associate Professor, Department of DVL, Santhiram Medical college and General Hospital, NH-40, Nandhyal, \\ Andhra Pradesh, INDIA. \\ Email: sumohita88@gmail.com
}

\begin{abstract}
Background: Alopecia Areata (AA) is a common, chronic autoimmune disease causing non- scarring hair loss of scalp and body hairs. The course of the disease is unpredictable that results in a severe psychological impact on the people. Aims and objectives: To study clinical patterns of Alopecia areata and it's association with other diseases. To study the dermatoscopy findings of AA. Materials and methods: The study was conducted in 50 people of both sexes between ages (1-50yrs) with Alopecia Areata attending the department of DVL at Santhiram medical college and general hospital for 6 months. The patient's data was recorded in a prestructured proforma that includes clinical history, general and cutaneous examination, investigations and dermatoscopy. Results: Out of 50 people( 29 males, 21 females). Common age group affected was $10-20 y r s$.Scalp involvement in $80 \%$ cases with (patchy alopecia $80 \%$, ophiasis $15 \%$, diffuse $5 \%$ ).beard in $10 \%$, eyebrows and eyelashes in $8 \%$, body hair in $4 \%$. Nail changes in AA were Pitting seen in $8 \%$ cases and longitudinal ridging in $6 \%$ cases. No nail changes in $86 \%$ cases. Alopecia areata was associated with atopy in $48 \%$, hypothyroidism in $18 \%$, vitiligo in $4 \%$, AA was not associated with other diseases in 30\%. Dermatoscopy findings were yellow dots in $45 \%$, black dots in $32 \%$, exclamatory mark $30 \%$, white dots in $10 \%$ broken hairs in $15 \%$, bent hair in $5 \%$ vellus hair in $2 \%$ Conclusion: Scalp was the most common site affected with the patchy type being a most common pattern. Alopecia areata was commonly associated with atopic dermatitis. The most common Dermatoscopy features were yellow dots(YD), black dots(BD), and exclamatory marks.

Key words: Alopecia areata(AA), Black dots(BD), Yellow dots(YD)
\end{abstract}

*Address for Correspondence:

Dr K Sumohita, Post graduate, Department of DVL, Santhiram Medical college and General Hospital, NH-40, Nandhyal, Andhra Pradesh.

Email: sumohita88@gmail.com

Received Date: 02/08/2020 Revised Date: 12/09/2020 Accepted Date: 27/10/2020

DOI: https://doi.org/10.26611/10211633

This work is licensed under a Creative Commons Attribution-NonCommercial 4.0 International License. $(\mathbf{c c})$ BY-NC

\begin{tabular}{|l|l|}
\hline \multicolumn{2}{|c|}{ Access this article online } \\
\hline Quick Response Code: & Website: \\
\hline & www.medpulse.in \\
\cline { 2 - 2 } & \\
\hline
\end{tabular}

\section{INTRODUCTION}

Alopecia areata (AA) is a common, chronic inflammatory disease that causes non- scarring hair $\operatorname{loss}^{1}$ It affects $1 \%$ of the general population although the pathogenesis of alopecia areata is still not completely understood, genetic environmental and autoimmune factors are considered to play a role in it's etiology. ${ }^{1}$ Alopecia areata is a T cellmediated organ-specific autoimmune disease and is associated with various autoimmune disorders such as vitiligo, atopy, Hashimoto's thyroiditis, diabetes mellitus, psoriasis, celiac disease, and lupus erythematosus. ${ }^{1}$ The characteristic initial lesion of alopecia areata is a circumscribed, hairless, smooth patch. ${ }^{1}$ Short, easily extractable broken hairs, known as exclamation mark hairs, are often seen at the margins of the bald patches during active phases of the disease. ${ }^{1}$.The incidence of Alopecia areata is $0.1-0.2 \%{ }^{1}$ Shuster described the "coudability" sign to differentiate diffuse AA from other alopecias, in AA normal looking hair kinks when forced inwards ${ }^{2}$ Histopathology -The swarm of bees appearance 
due to dense peribulbar lymphocytic infiltrate characterizes the acute phase of A.A. ${ }^{2}$ On Dermatoscopy, active disease is characterized by yellow dots, black dots, "exclamation mark" or tapering hairs, and broken hairs. Vellus hair in lesions is another marker of AA and may indicate late or inactive disease ${ }^{3,4}$.

\section{AIMS AND OBJECTIVE:}

Aims and objectives: To study clinical patterns of Alopecia areata and it's association with other diseases. To study the dermatoscopy findings of AA.

\section{PATIENTS AND METHODS}

The study group includes 50 patients of both sexes between ages 1-50 yrs with alopecia areata attending to the department of DVL OPD in Santhiram medical college and general hospital, Nandyal during the period from september 2019 to February 2020. All patients of ages 1$50 \mathrm{yrs}$ of both sexes with the clinical diagnosis of alopecia areata willing to give informed written consent were included in the study. Patients who are not willing to give informed consent and patients of alopecia areata already on treatment were excluded. Approval for the study was taken from the Institutional ethical committee. Written informed consent was taken from patients. A detailed history and clinical examination findings were recorded as per the prestructured proforma. Clinical photographs and dermatoscopy images were taken The skin, hair, nails, and mucosa were examined in detail. Relevant investigations were done.

\section{RESULTS}

The Study population includes 50 cases of Alopecia areata(AA) Out of 50 cases $58 \%$ were males, $42 \%$ were females. Male to female ratio was 1.38:1, AA according to age in age groups $1-10 \mathrm{yrs}$ was $32 \%, 11-20 \mathrm{yrs}$ was $36 \%$, 21 $30 \mathrm{yrs}$ was $16 \%, 31-40 \mathrm{yrs}$ was $12 \%, 41-50 \mathrm{yrs}$ was $2 \%$. AA was common in age groups(11-20yrs). The most common site of AA was Scalp 80\%, Most common type in scalp AA was patchy alopecia ( $80 \%$ ). Ophiasis was seen in $15 \%$, and diffuse alopecia areata in $5 \%$. Other sites involved in Alopecia areata were beard in $10 \%$, eyebrows, and eyelashes in $4 \%$ body hair in $2 \%$. Alopecia totalis was $2 \%$, alopecia Universalis was $2 \%$. Nail changes in Alopecia areata were Pitting seen in $8 \%$ cases and longitudinal ridging in $6 \%$ cases, no nail changes in $86 \%$ cases. Alopecia areata was associated with atopy in $48 \%$, Hypothyroidism in $18 \%$, and vitiligo in $4 \%$, AA was not associated with other diseases in 30\%. Dermatoscopy findings were yellow dots in $46 \%$, black dots in $32 \%$, exclamatory mark in $30 \%$, white dots in 10 broken hairs in $16 \%$, bent hair in $3 \%$ vellus hair in $2 \%$.

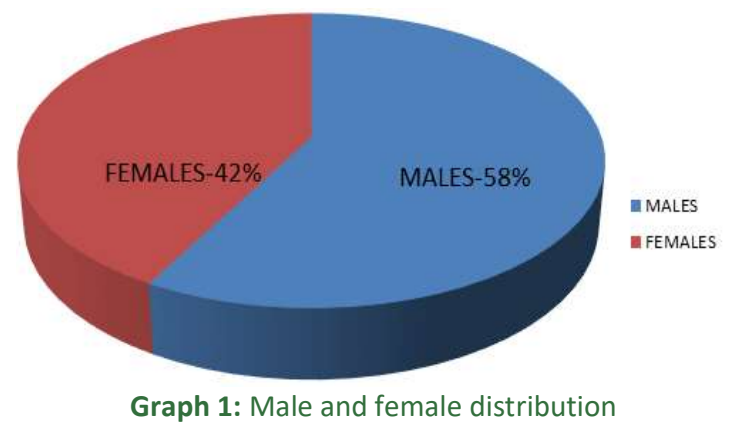

Table 1: Distribution of cases according to Age and sex

\begin{tabular}{cccc}
\hline AGE & CASES & MALES & FEMALES \\
\hline $1-10$ & $16(32 \%)$ & $10(20 \%)$ & $6(12 \%)$ \\
$11-20$ & $18(36 \%)$ & $11(22 \%)$ & $7(14 \%)$ \\
$21-30$ & $8(16 \%)$ & $5(10 \%)$ & $3(6 \%)$ \\
$31-40$ & $6(12 \%)$ & $4(8 \%)$ & $2(4 \%)$ \\
$41-50$ & $2(4 \%)$ & $1(2 \%)$ & $1(2 \%)$ \\
\hline
\end{tabular}

Table 2: Site of distribution of Alopecia areata

\begin{tabular}{cc}
\hline Site of AA & Cases \\
\hline Scalp & $40(80 \%)$ \\
Beard & $5(10 \%)$ \\
Eyebrow and eyelashes & $2(4 \%)$ \\
Body hair & $1(2 \%)$ \\
Alopecia totalis & $1(2 \%)$ \\
Alopecia universalis & $1(2 \%)$ \\
\hline
\end{tabular}

Table 3: Pattern of distribution of AA on scalp( out of 40)

\begin{tabular}{cc}
\hline Pattern of distribution & Cases \\
\hline Patchy & $32(80 \%)$ \\
Ophiasis & $6(15 \%)$ \\
Diffuse & $2(5 \%)$
\end{tabular}

Graph 2: Nail changes in AA

\begin{tabular}{cc}
\hline Nail changes & cases \\
\hline Pitting & $(4) 8 \%$ \\
Longitudinal Ridging & $(3) 6 \%$ \\
No nail changes & $(43) 86 \%$ \\
\hline
\end{tabular}

Table 4: Associated diseases with AA Associated diseases Cases

Atopy 24(48\%)

Hypothyroidism 9(18\%)

Vitiligo 2(4\%)

AA not associated with diseases $\quad 15(30 \%)$

Table 5: Dermatoscopy changes in AA

\begin{tabular}{cc}
\hline Dermatoscopy changes & Cases \\
\hline Yellow dots & $23(46 \%)$ \\
Black dots & $16(32 \%)$ \\
Exclamatory marks & $15(30 \%)$ \\
White dots & $5(10 \%)$ \\
Broken hairs & $8(16 \%)$ \\
Bent hair & $3(6 \%)$ \\
Vellous hair & $1(2 \%)$ \\
\hline
\end{tabular}


Clinical photographs

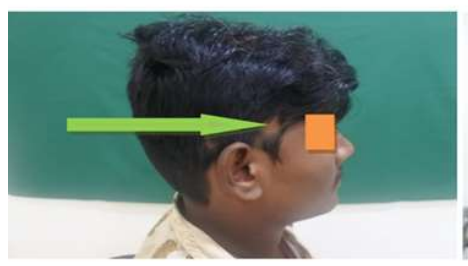

Figure 1: Patchtype of alopecia areata

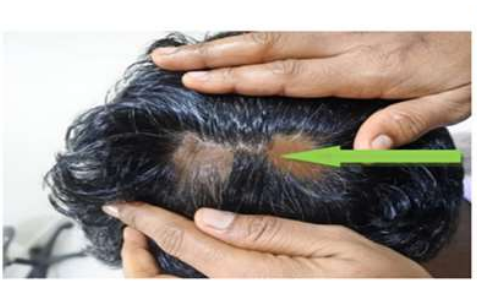

Figure 2: Patch type of AA

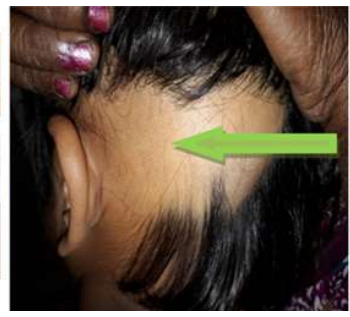

Figure 3: Ophiasis

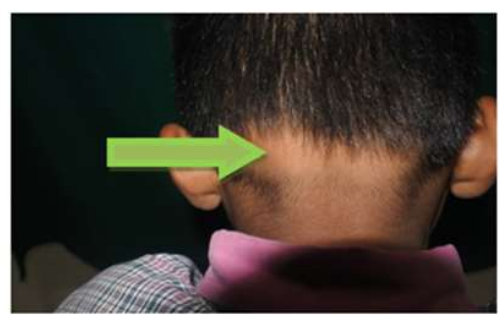

Figure 4: Alopecia areata involving occipital area

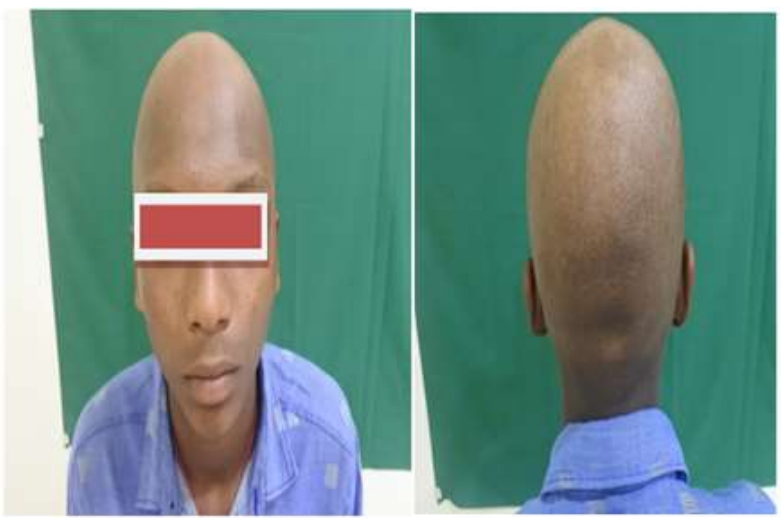

Figure 5: Alopecia totalis

\section{DERMATOSCOPY IMAGES}

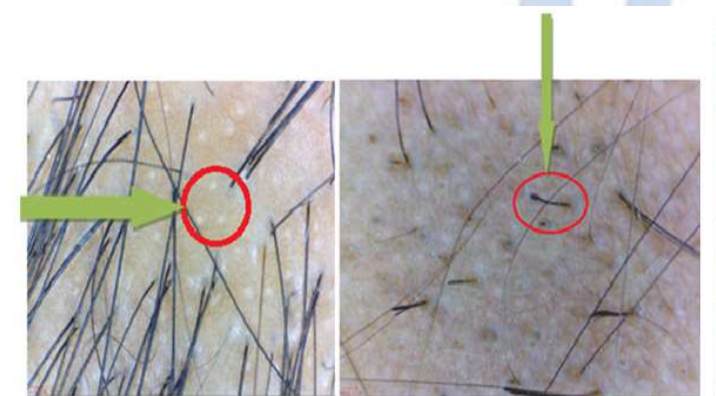

Figure 6: White dots; Figure 7: Exclamatory mark sign

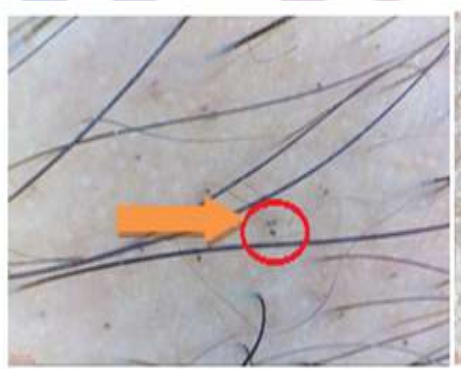

Figure 8: Broke hair

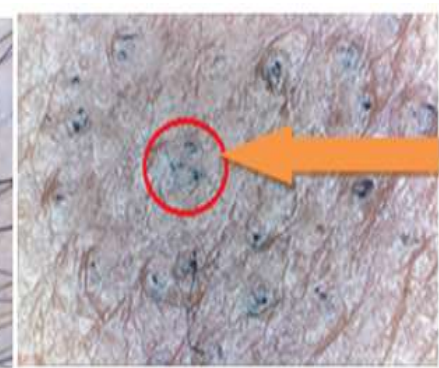

Figure 9: Hidden hair

\section{DISCUSSION}

Alopecia areata is a common chronic inflammatory disease causing non- scarring form of hair loss. AA affects both sexes equally though in some studies there was a preponderance for males. Our study included 50 patients of alopecia areata of both sexes of which $58 \%$ were males and $42 \%$ were females. The male to female ratio was $1.38: 1$. This was similar to the study reported by Arun Achar et al. ${ }^{1}$, where males and females affected were $(50.24 \% \text { and } 49.8 \% \text {, respectively })^{5}$. In a study conducted by Sharma et al., there was a slightly higher incidence among males. The age of participants in our study ranged from 5-50yrs. The most common age group affected was 11-20yrs ( $36 \%$ ) which was similar to a study done by Wasserman et al., ${ }^{6}$ in which more cases of AA were seen before 20 years of age. The most common site of AA in our study was Scalp $84 \%$ (patchy alopecia $80 \%$, ophiasis $15 \%$, diffuse $5 \%$ ), other sites involved in AA were beard $10 \%$, eyebrows and eyelashes $4 \%$,body hair $2 \%$. Alopecia totalis was seen in $2 \%$, Alopecia Universalis is $2 \%$. The scalp was the most common site affected in AA (90\%) which was similar to study conducted by Tan et al.., $2002,{ }^{7}$. In Bapu et al..'s study, ${ }^{8}$ patchy (65.5\%), ophiasis (4.31\%) types were most commonly seen. Nail changes in our study were Pitting seen in $8 \%$ cases and longitudinal ridging seen in $6 \%$ cases, no nail changes in $86 \%$ cases. Gandhi et al. reported superficial pits as the commonest change ${ }^{9}$. Nail changes were described in $7 \%$ to $66 \%$ of AA patients with nail pitting the common type. ${ }^{10}$ The association of Alopecia areata with atopic dermatitis was $48 \%$, A study conducted by S Sukhjot et al.; ${ }^{11}$ has reported that $50 \%$ cases of AA had Atopy, similar to our study. Hypothyroidism was $18 \%$ in our study which was similar to Ola A Bakry et al. study ${ }^{12}$ where hypothyroidism was 
seen in $16 \%$ of cases. AA with vitiligo was $4 \%$ in our study which was similar to a study conducted by Jesy Ragavan et al.,${ }^{13}$ were vitiligo was noted in 5\% subjects suggesting an association between AA and vitiligo. AA in 30\% of cases was not associated with any disease. Dermatoscopy findings in our study include yellow dots in $46 \%$, black dots in $32 \%$, exclamatory mark in $30 \%$, white dots in $10 \%$, broken hairs in $16 \%$, bent hair in 3\% vellus hair in $2 \%$ of patients, in contrast, to study conducted by Balachandar et $a l .{ }^{14}$ that showed yellow $\operatorname{dots}(50 \%)$, exclamation mark hairs $(60 \%)$, broken hairs, (30\%)black dots $(20 \%)$, short vellus hairs in $(10 \%)$.

\section{CONCLUSION}

Alopecia areata is a chronic autoimmune T-cell disorder of the hair follicle. The peak incidence of AA in our study was 11-20yrs. The scalp was the commonest site affected. Patchy type was the commonest pattern. Pitting of nails was the most common nail change. Alopecia areata was commonly associated with atopic dermatitis. Most common dermatoscopic finding was yellow dots. Other common dermatoscopic findings were black dots, exclamatory marks and broken hair.

\section{REFERENCES}

1. Andrew G. Messenger1, Rodney D. Sinclair, Paul Farrant and David A. R. de Berker,Department of Dermatology, Royal Hallamshire Hospital, Sheffield, UK, Acquired disorders of hair, Rooks textbook of dermatology Volume 3, $9^{\text {th }}$ edition, pg no- 89.28-89.32.

2. Rachita Dhurat, Sukesh M.S, chapter39 ,Hair and scalp disorders,IADVL textbook of dermatology, volume $2,4^{\text {th }}$ edition.pg-no1515.

3. Mubki T, Rudnicka L, Olszewska M, Shapiro J. Evaluation and diagnosis of the hair loss patient: Part II.
Trichoscopic and laboratory evaluations. J Am Acad Dermatol. 2014;71:431.e1-431.e11.

4. Mane M, Nath AK, Thappa DM. Utility of dermoscopy in alopecia areata. Indian J Dermatol. 2011;56:407

5. Arun Achar, Sanjay K Rathi*, Leishiwon Kumrah, Rabindranath Biswas, Samiran Bisai Clinicoepidemiological study of alopecia areata Journal of Pakistan Association of Dermatologists. 2018; 28 (2): 168174,

6. Wasserman D, Guzman-Sanchez DA, ScottK, McMichael A. Alopecia areata. Int JDermatol 2007; 46: 121-31..

7. Tan, E., Tay, Y.-K., Goh, Ch.-L., et al., 2002. The pattern of alopecia areata in Singapore - a study of 219 Asians. Int. J.Dermatol. 41, 748-753

8. Bapu NG, Chandrashekar L, Munisamy M, Thappa DM, Mohanan S. Dermoscopic findings of alopecia areata in dark skinned individuals: An analysis of 116 cases. Int J Trichology. 2014;6:156-9.

9. Gandhi V, Baruah MC, Bhattacharya SN. Nail changes in alopecia areata: incidence and pattern. Indian J Dermatol Venereol Leprol. 2003;69:114-5

10. Kasumagic-Halilovic E, Prohic A. Nail changes in alopecia areata: frequency and clinical presentation. J Eur Acad Dermatol Venereol. 2009;23:240-1.

11. Sukhjot S, Sharma VK, Kumar L, KumarB. Atopy and alopecia areata in NorthIndians. Indian J Dermatol Venereol Leprol 2001;67:231-3

12. Ola A Bakry, Mohamed A Basha, Maather K El Shafiee, ${ }^{1}$ and Wafaa A Shehata Thyroid Disorders Associated with Alopecia Areata in Egyptian Patients Indian J Dermatol. 2014 Jan-Feb; 59(1): 49-55

13. Raghavan JS et al.. Epidemiological and clinical characteristics of alopecia areata: an observational study from South India Int J Res Dermatol. 2018 Aug;4(3):313317

14. Balachandar et al.1 Trichoscopy of Alopecia Areata: A Diagnostic Aide Hair : Therapy and Transplantation june $26^{\text {th }} 2014$

$$
\text { Source of Support: None Declared }
$$$$
\text { Conflict of Interest: None Declared }
$$ 